\title{
Luis Alarcón Meneses. Colombia: Historia, Educación y Política. Miradas Múltiples. Barranquilla: Sello Editorial Universidad del Atlántico, 2019.
}

DOI: https://doi.org/10.15648/hc.39.2021.2967

El libro que se reseña a continuación es el resultado de los distintos ejercicios de investigación que se desarrollan dentro del Grupo de Investigaciones Históricas en Educación e Identidad Nacional, liderado por Luis Alarcón Meneses. En el texto, se abordan una diversidad de temáticas de actual discusión historiográfica en Colombia y América Latina, como es el caso de la revaloración de algunos temas asociados a la educación, la justicia, la política, la violencia y lo religioso desde principios del siglo XVI.

En relación a su organización metodológica, la obra está estructurada en tres partes fundamentalmente. La primera, denominada Educación e Historia contiene dos capítulos. El primero, Representaciones e imaginarios sobre la educación intercultural en los estudiantes universitarios en el Caribe colombiano. El caso de la Universidad del Atlántico, presentado por Celmira Castro y Rosa Rodríguez Izquierdo. Esta es una investigación sociológica a través de la cual se estudian las representaciones y los imaginarios de la educación intercultural en los estudiantes de la Universidad del Atlántico. Para ello, las autoras escogieron tres grupos focales a entrevistar: afrocolombianos, indígenas y mestizos, y organizaron metodológicamente las preguntas en 4 categorías claves. En ese sentido, el estudio ofrece una valoración cualitativa interesante, toda vez que aporta aspectos relacionados con la aceptación de la multiculturalidad, la formación de profesores para la educación intercultural, las concepciones sobre interculturalidad, y el currículo intercultural o dimensión intercultural de la educación superior. 
Por su parte, Iván Valencia nos presenta el otro capítulo, titulado Diálogos entre la historia y la educación: una reflexión epistemológica al concepto de formación integral desde la complejidad. En este trabajo se "aborda la reflexión alrededor de la educación como ejercicio formativo, cultural y social. Analiza la educación desde su perspectiva histórica, ubicando al lector en las diferentes tendencias y miradas conceptuales que han jugado un papel preponderante en el ejercicio educativo" ${ }^{1 "}$.

La segunda parte denominada Violencia, Justicia y Política, está compuesta por cinco artículos que revisan diferentes facetas de la historia de Colombia desde la primera década del siglo XIX hasta principios del XXI. El texto inicial Ladrones y rebeldes en la provincia de Popayán, 1810-1820, de Willian Chapman Quevedo, estudia la participación social y política del "bajo pueblo" en el marco del proceso de independencia en la sociedad payanesa. Para ello, analiza las acciones de algunos grupos sociales a través de sumarios que se adelantaron por robo y traición a la patria, sobre los cuales considera que "el comportamiento de éstos no estuvo sujeto exclusivamente a lo delictivo, sino que tenían implícitos matices políticos propios de su cotidianidad ${ }^{2}$.

Después, revisa a través de la prensa y algunos juicios, cómo las autoridades intentaron contrarrestar la conducta delictiva, específicamente la concerniente al abigeato a través del establecimiento de normas para controlar el robo de ganado ${ }^{3}$. En general, el autor trata de mirar cómo los grupos pertenecientes al "bajo pueblo" asumieron ese periodo de incertidumbre social, económica, religioso y político, que trastocó su cotidianidad, obligándolos a cambiar su modus vivendi con el objetivo

1 Valencia-Martínez, Iván. "Diálogos entre la historia y la educación: una reflexión epistemológica al concepto de formación integral desde la complejidad" En Colombia: Historia, Educación y Política. Miradas Múltiples, editado por Luis Alfonso Alarcón Meneses. Barranquilla: Ediciones Universidad del Atlántico, 2019, 9.

2 Chapman- Quevedo, Willian. "Ladrones y rebeldes en la Provincia de Popayán, 1810-1820. En Colombia: Historia, Educación y Política. Miradas Múltiples, editado por Luis Alfonso Alarcón Meneses. Barranquilla: Ediciones Universidad del Atlántico, 2019, 70.

3 Chapman- Quevedo, Willian. "Ladrones y rebeldes en la Provincia de Popayán, 71. 
de adaptarse a los cambios que se generaron en el transito del sistema monárquico al republicano ${ }^{4}$.

El segundo, titulado El discurso de la guerra en la Nueva Granada entre 1839-1842, es presentado por las historiadoras Melvys López y Eva García. Las autoras, a partir del análisis de las proclamas difundidas por los coroneles y generales que lucharon en la Guerra de los Supremos, identificaron algunas de las justificaciones que estos actores utilizaron para legitimar su accionar guerrero frente al gobierno. También, logran demostrar cómo desde los dos bandos en conflicto se construyó una imagen del enemigo a través el "discurso guerrero". A los agentes estatales se les asocio con unas características morales como la ambición, la crueldad y la tiranía, y a los insubordinados como traidores de la patria. Así, concluyen que "los discursos justificadores en los cuales se mostraban que acudir a las armas era una forma de reclamar justicia que al no ser brindada tenía que exigirse. La creación de un discurso en el cual los representantes de la ley en la administración Márquez eran simbolizados como déspotas que solo respondían a sus intereses personales permitió legitimar la guerra 5".

Por otra parte, Edwin Monsalvo, Héctor López y Miguel Suárez nos presentan el tercer capítulo, titulado De niño a delincuente: los menores infractores en la mira de la justicia local. Manizales (Colombia), 1859-1897. El trabajo analiza el discurso y las prácticas de los alcaldes y jueces parroquiales de Manizales frente a los menores delincuentes, así como las respuestas de estos y sus familiares para escapar de las acciones judiciales. Demuestran, cómo hubo un especial cuidado sobre los menores infractores, "castigando a los padres o responsables no como una manera de penar el delito, sino de atacarlo en su raíz mediante la aplicación de una justicia ejemplarizante ${ }^{6 "}$. Lo anterior, bajo la hipótesis

4 Chapman- Quevedo, Willian. "Ladrones y rebeldes en la Provincia de Popayán, 85

5 López-Solorzano, Melvys y Eva García Charris. "El discurso de la guerra en la Nueva Granada entre 1839-1842”. En Colombia: Historia, Educación y Política. Miradas Múltiples, editado por Luis Alfonso Alarcón Meneses. Barranquilla: Ediciones Universidad del Atlántico, 2019, 109.

6 Monsalvo-Mendoza, Edwin; Héctor López- Castrillón y Miguel Suárez- Araméndiz. "De niño a delincuente: los menores infractores en la mira de la justicia local. Manizales (Colombia), 1859- 1897”. En Colombia: Historia, Educación y Política. Miradas Múltiples, editado por Luis Alfonso Alarcón Meneses. Barranquilla: Ediciones Universidad del Atlántico, 2019, 116. 
de que "gran parte de los alcaldes, comisarios, procuradores, vecinos, familiares y niños implicados, compartieron un imaginario jurídico, policial y social que explicaba las practicas transgresoras de los "hijos de familia" como una consecuencia directa de la mala influencia de los adultos, y no como un acto consciente y malintencionado de los mismos infantes"?.

El cuarto capítulo nos lo presenta Muriel Jiménez Ortega, titulado Militares y civiles en las políticas de seguridad del Frente Nacional 1958-1974. En este, la autora estudia las relaciones establecidas entre civiles y militares en la coyuntura mencionada. Para ello, revisa las discusiones sobre las prerrogativas militares y los diseños de carácter institucional que permitieron el desarrollo de una autonomía militar limitada y subordinada al poder civil. Además, revisa cómo las políticas de seguridad nacional estuvieron orientadas desde marcos ideológicos y políticos anticomunistas, a la vez que, identifica las percepciones de los civiles y los militares en el tratamiento de las "nuevas" y "viejas" violencias.

Finalmente, concluye que estas relaciones "se afincaron sobre el retorno de los principios de la constitución vigente. Los niveles de autonomía y prerrogativas otorgadas a las fuerzas militares se construyeron dentro del principio de subordinación, como lo evidencian los diseños institucionales de tipo administrativos y operacional del periodo. En ese sentido, lejos de establecerse un aislamiento de los civiles de las políticas de seguridad, lo que existió fueron marcos ideológicos y políticos cohesionadores entre las elites civiles y militares que orientaron el tratamiento de las "nuevas" violencias, caracterizadas, entre otras, por el surgimiento de guerrillas de inspiración marxista".

El último capítulo de esta sección, se titula La política exterior colombiana: de Pastrana a Uribe, de Roberto González y Francisco Eversley.

7 Monsalvo-Mendoza, Edwin; Héctor López- Castrillón y Miguel Suárez- Araméndiz. "De niño a delincuente, 117.

8 Jiménez-Ortega, Muriel. "Militares y civiles en las políticas de seguridad del Frente Nacional 19581974”. En Colombia: Historia, Educación y Política. Miradas Múltiples, editado por Luis Alfonso Alarcón Meneses. Barranquilla: Ediciones Universidad del Atlántico, 2019, 167. 
Es un trabajo presentado desde el enfoque de la historia de las relaciones internacionales, donde se estudia de forma comparativa la política exterior colombiana, la subordinación hacia Estado Unidos y la internacionalización del conflicto armado en ambos periodos presidenciales. Los autores consideran que la prevalencia de las continuidades de la política exterior del país en relación a los vínculos con los Estados Unidos en las últimas décadas puede entenderse desde dos orillas. "Por un lado, resaltando las bondades de esa fructífera relación, y por el otro, el precio que ha tenido que pagar el país en materia de subordinación y dependencia política a Washington. Esto último sin duda, ha afectado profundamente las relaciones del país con el vecindario y disminuido las posibilidades de un mayor liderazgo regional ${ }^{9 ”}$.

El último apartado denominado Historia del Caribe, está compuesto por tres capítulos que estudian diferentes aspectos del Caribe colombiano. Luis Manuel Pérez nos presenta el primero, titulado La iglesia medieval en el Nuevo Reino: las ordenes mendicantes e iglesia secular dos maneras de la cristiandad en la provincia de Santa Marta (Colombia), 1526-1536. En este trabajo se analiza la relación entre la labor mendicante y su pasado medieval en la Tierra Firme. Asimismo, estudia los inconvenientes que afectaron la labor misionera de los religiosos y la forma cómo se estableció la iglesia en la provincia de Santa Marta, por lo que, en últimas, nos ofrece una descripción sobre los primeros momentos de esta institución en la ciudad.

Por su parte, Tomás Caballero Truyol nos presenta De las fiestas patronales de San Nicolás de Tolentino a la erección de la Diócesis de Barranquilla (Colombia), 1870-1937. En esta investigación se examina cómo se originó y consolidó el proyecto evangelizador del catolicismo en Barranquilla en la época abordada. Para tal fin, el autor organizó el texto en 4 partes claves: primero, describe de qué manera se organizaban y realizaban las primeras manifestaciones religiosas en la ciudad. Después, estudia el conflicto religioso y político que se presentó entre

9 Gonzáles- Arana, Roberto y Francisco Eversley Torres. "La política exterior colombiana: de Pastrana a Uribe". En Colombia: Historia, Educación y Política. Miradas Múltiples, editado por Luis Alfonso Alarcón Meneses. Barranquilla: Ediciones Universidad del Atlántico, 2019, 189. 
las parroquias de San Nicolás y San Roque, que tuvo como consecuencia la anexión de ésta última a la diócesis de Santa Marta.

En la tercera parte, explica cómo a partir de las buenas relaciones que se dieron entre la Iglesia y el Estado en el gobierno de Rafael Núñez, se construyeron en la ciudad una diversidad de templos y colegios religiosos. Esto obedeció a que "el clero nacional invitó a otras comunidades religiosas como los jesuitas, los salesianos y los capuchinos para que se establecieran en el país y evangelizaran a los pueblos donde el catolicismo no tenía presencia ${ }^{10}$ ". Es así como a Barranquilla llegan varias misiones a fortalecer la vida espiritual a través de la construcción de nuevas iglesias, colegios y obras pías; proceso que terminó con la erección de la diócesis de Barranquilla en 1932. Por último, estudia cómo paralelo a la apertura de estas instituciones, se fueron creando hermandades y cofradías que contribuyeron con obras pías al desarrollo espiritual y material de Barranquilla.

El capítulo que cierra la última sección es presentado por Ángela Agudelo González, titulado Imagen de ciudad. Las fotografías publicadas en el Directorio Comercial Pro-Barranquilla y El Álbum de Cartagena de Indias durante la década del 20 del siglo XX. Es un estudio que demuestra cómo la elite barranquillera y cartagenera utilizaron las fotografías a través de dos publicaciones donde se publicitó la ciudad, con el objetivo de construir una imagen progresista y moderna en la primera mitad del siglo XX. Este esfuerzo se circunscribe en un contexto regional en el que estas ciudades experimentaban procesos de modernización, sobre todo en el aspecto urbano. Por lo que buscaron cada una a su modo, configurarse como eje político y económico de la región. Finalmente, Agudelo concluye que "ambos textos, nos muestran las tensiones que existieron entre ambas ciudades por demostrar que eran los puertos más importantes del Caribe colombiano. Y lo hicieron generando una estrategia de 'mercadeo' para atraer principalmente a

10 Caballero- Truyol, Tomás. "De las fiestas patronales de San Nicolás de Tolentino a la erección de la Diócesis de Barranquilla (Colombia), 1870-1937”. En Colombia: Historia, Educación y Política. Miradas Múltiples, editado por Luis Alfonso Alarcón Meneses. Barranquilla: Ediciones Universidad del Atlántico, 2019, 230. 
comerciantes extranjeros, como lo demuestra el hecho de que se encontrara escrito en español-inglés ${ }^{11 "}$.

En definitiva, la obra constituye un aporte clave para la historiografía nacional, y en particular a la del Caribe Colombiano. La variedad de investigaciones aquí expuestas nos permite acercarnos a visiones renovadas de los problemas presentados, como es el caso en torno a lo educativo, la violencia, la justicia y la política. En ese mismo sentido, la tercera parte del texto nos propone una historia sobre el hecho religioso en la región, tema que muy poco se ha explorado. Esta última, termina con una investigación que nos sugiere empezar a entender las dinámicas regionales de la primera mitad del siglo XX en la región Caribe desde una perspectiva comparativa más amplia y compleja.

Jesús Castro Fontalvo Historiador y Magíster por la Universidad del Atlántico (Colombia). Cafon1994@gmail.com

11 Agudelo-González, Ángela. "Imagen de ciudad. Las fotografías publicadas en el Directorio Comercial Pro-Barranquilla y El Álbum de Cartagena de Indias durante la década 20 del siglo XX". En Colombia: Historia, Educación y Política. Miradas Múltiples, editado por Luis Alfonso Alarcón Meneses. Barranquilla: Ediciones Universidad del Atlántico, 2019, 269. 